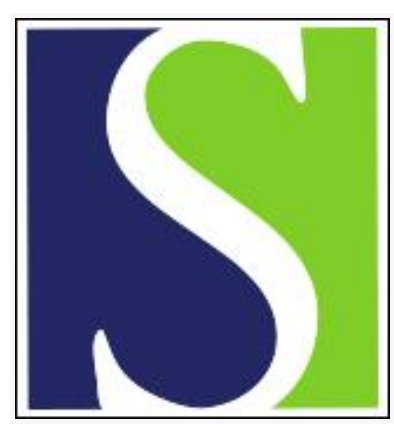

Scand J Work Environ Health 1995;21(6):521-522

https://doi.org/10.5271/sjweh.70

Issue date: Dec 1995

\title{
Occupation and suicide
}

by Partanen T, Jourenkova N, Welp E, Johansson M

This article in PubMed: www.ncbi.nlm.nih.gov/pubmed/8824760

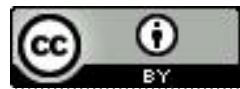




\section{Occupation and suicide}

Drs Boxer, Burnett, and Swanson at the National Institute for Occupational Health and Safety (NIOSH) in the United States recently published a review of studies on occupation and suicide (1). Numerous job titles were suggested as groups of high risk. For example, high suicide rates have been consistently recorded for physicians in Denmark, Finland, Sweden, and the United States. A questionnaire study undertaken by the Danish Young Physicians' Association (2) reported that $10 \%$ of Danish physicians have considered taking their life, and $0.5 \%$ have attempted it. The woman to man ratio of those having considered was $3: 1$.

On occasion, excess suicide rates have been reported for veterinarians and nurses. Chemists represent another high-risk group. The recurring excesses observed among farmers may be related to economic instability, isolation, and possibly also exposure to agrochemicals. Male police officers in Buffalo, New York, in the United States, exhibited a threefold rate compared with other municipal employees (3). Buffalo police officers undergo an extensive psychiatric preemployment screening; hence, the high rates probably reflect job stress.

Suicide rates are not consistently associated with socioeconomic status across populations and time periods. It seems, for example, that Swedish men with a high socioeconomic status have low rates but $S$ wedish women with a high socioeconomic status have high rates.

Russian statistics on suicides are now available (4). The male rate in the Russian Federation was a high 66 per 100000 in 1984, but it had dropped to $40 \%$ by 1988 . Over a four-year period (1984-1988), a 34\% decline was recorded in the entire Soviet Union after the introduction of severe restrictions on alcohol sales.

The occupational background for suicides has not been extensively studied in Russia because interest in the prevention of suicides developed relatively late. However, studies published around 1970 mention unresolvable difficulties at work, problems in qualifications for work, a downward shift or fall in professional status, and migrant work as important factors behind suicides (5). Be it mentioned in this context that, in the Baltic nations, male suicide rates dropped in 1985-1987, but rocketed subsequently up to $60-75$ per 100000 in 1993 . Societal reasons were suspected to be responsible for the fluctuations (6).

In Denmark, suicide rates have been on the increase for young ( $25-34$ years) and old $(\geq 75)$ men. The Danish rates for 25 - to 34 -year-old men (26 per 100000 in
1993) are higher than in Norway, Sweden, Germany, France, and Italy, for example. But the highest rates for young men were recorded in 1993 in the Russian Federation (82 per 100000 ), Lithuania (72 per 100000 ), Estonia (70 per 100000 ), Belarus (58 per 100000 ), and Finland (56 per 100000 ). In 1993, Finnish women had the highest rate in the world (13 per 100000$)$ (7). The Dutch rates were 18 per 100000 per year for all men and 9 per 100000 for all women around the time of the peak rates recorded in the Soviet Union, and they have been decreasing since, especially among women.

The NIOSH scientists point to the widespread belief that official suicide rates are underestimates (sometimes they may be overestimates), but no one knows the extent of the bias in any population and time period. Even $70 \%$ of all suicide cases have been claimed to be unreported (5). Closer scrutiny of violent deaths among the Buffalo police force revealed a significant number of suicidal deaths not classified as suicides on the death certificate (8). The sensitivity of suicidal deaths was estimated at 0.86 .

The causes of suicides are complex social, psychological, and behavioral matters. Dramatic increases in depression have been reported in epidemiologic studies for those born after World War II. Work (and lack of it) may involve hazards, but work can also act as protection. One should take a serious look at high-risk occupations such as physicians, nurses, farmers, and other groups, such as young men, in order to attempt prevention. Workplace measures can be considered, and occupational and other health care units should look for signs such as heavy consumption of alcoholic beverages and depressiveness among the employed and the unemployed, the earlier the better.

\section{References}

1. Boxer PA, Burnett C, Swanson N. Suicide and occupation: a review of the literature. J Occup Environ Med 1995;35:44252.

2. Foreningen af Yngre Laeger. Yngre laegers arbejds- og livsvillkor [Young physicians' occupational and living conditions]. Copenhagen: Foreningen af Yngre Laeger, 1990.

3. Vena JE, Violanti JM, Marshall J, Fiedler RC. Mortality of a municipal worker cohort III: police officers. Am J Ind Med 1986;10:383-7.

4. Wasserman D, Varnik K, Eklund G. Male suicides and alcohol consumption in the former USSR. Acta Psychiatr Scand 1994:89:306-13.

5. Miller MA, Miller YN. Suicide and suicidology in the Soviet 
Union. Suicide Life Threat Behav 1988:18:303-21.

6. Wasserman D, Varnik A. Increase in suicide among men in the Baltic countries. Lancet 1994;343:1504-5.

7. World Health Organization (WHO). World health statistics annual 1994. Geneva: WHO, 1995.

8. Violanti JM. Validity of police suicide rates [abstract]. Epidemiology 1995;6:\$129.

Timo Partanen, PhD, ${ }^{1}$ Nadejda Jourenkova, MD, ${ }^{2}$ Esther Welp, MSc, ${ }^{3}$ Mauri Johansson, $M D^{4}$
1 Finnish Institute of Occupational Health Topeliuksenkatu 41 a $\mathrm{A}$ FIN-00250 Helsinki, Finland

2 Institute of Carcinogenesis NN Blokhin Cancer Research Centre Moscow, Russian Federation

3 Department of Environmental Health University of Washington, Seattle, United States

4 Aarhus County, Denmark 